\title{
Cost of illness of community-acquired pneumonia. Review of the literature and possible strategies in the Serbian health care setting
}

\author{
Vojislav Cupurdija ${ }^{1}$, Zorica Lazic ${ }^{1,2}$, Mihajlo Jakovljevic ${ }^{2}$ \\ Department of Pharmacology and Toxicology, The Faculty of Medical Sciences University of Kragujevac, Serbia \\ Center for Pulmonary Diseases, Clinical Center Kragujevac, Kragujevac, Serbia
}

\begin{abstract}
Community-acquired pneumonia (CAP) represents a potentially severe illness with high incidence and significant economic impact. The estimated incidence varies from 1.6 to $13.4 \mathrm{cases} / 1000$ inhabitants per year. Its burden of disease is attributed to high morbidity, mortality and serious health care utilization and expenditure throughout the world. The identification of determinants of high treatment costs could help in defining strategies for their reduction and more efficient use of the existing resources. In this article, a review of the existing literature about CAP cost-of-illness is provided, together with some considerations about possible strategies to decrease CAP costs in the Serbian health care setting. Available reports from cost-of-illness trials of CAP are relatively scarce. Most of them highlight the high costs generated by treatment protocols, with important differences between inpatients and outpatients. The inpatient cases of CAP varies from 18 to $60 \%$. The therapy represents 10 to $15 \%$ of the overall costs of CAP. The costs of CAP treatment among inpatients are 7.9 times higher than those in outpatients. In case of complications and prolonged length of stay, this difference could even be 17 to 51 times higher. Frequent hospital admissions could be avoided, which would reduce the costs of CAP treatment. An important precondition for successful cost containment would be higher adherence to clinical guidelines, particularly reflected through Pneumonia Severity Index-a (PSI) application. Thus, it would be possible to significantly reduce the length of stay in hospital, in majority of patients, without jeopardizing their health or influencing the clinical course of illness.
\end{abstract}

\section{Keywords}

Community-acquired pneumonia; Cost of illness analysis; Costs; Health economics; Serbia

\section{COST OF ILLNESS: ANALYSIS APPROACH}

The awareness about health service resources limitation is increasing in medical circles throughout the world, and the number of studies dedicated to the use of these resources, often related to particular diseases, is increasing during recent years. Past few decades of dynamic development of health economics worldwide have brought new methodological approaches to medical care costs assesment. Cost-of-illness analysis is based on descriptive assessment of "real world"cost matrix associated with particular health conditions. These trials can be planned either as prospective or retrospective. Essentially, they mostly provide an in-depth follow up of patients suffering from certain disorder. Thus we get insight into both direct medical costs of care and indirect ones (e.g., productivity loss). Depending on perspective chosen (e.g., citizen, third party payer or society) most trials face difficulties to encompass all diseaserelated costs. In the attempt to resolve these methodological issues, cost analysis alongside clinical trials on efficiency have become the most widely exploited study design providing detailed picture on individual patient's services consumption and expenditure. This review aims at providing comprehensive comparison of up-to-date knowledge on community-acquired pneumonia economic consequences worldwide.

\section{COMMUNITY-ACQUIRED PNEUMONIA}

Community-acquired pneumonia (CAP) is defined as potentially severe disease with high incidence and significant economic
Corresponding author Dr. Mihajlo B. Jakovljevic Assistant Professor. Department of Pharmacology and Toxicology The Faculty of Medical Sciences. University of Kragujevac

Svetozara Markovica 69 34000 Kragujevac, Serbia Tel: + +38134306 800 ext 223; Fax: + + 38134 306800

jakovljevicm@medf. kg.ac.rs

\section{Disclosure}

The authors have no financial competing interest related to the topic of this article 
impact. It is commonly defined as an acute infection of the lung parenchyma that is associated with at least some symptoms of acute infection, accompanied by the presence of an acute infiltrate on a chest radiograph or auscultatory findings consistent with pneumonia (such as altered breathing sounds and/ or localized rales), in a patient not hospitalized or residing in a long-term-care facility for $>14$ days before onset of symptoms. The most common causative agents for CAP include Streptococcus pneumoniae, Mycoplasma pneumoniae, Chlamydia pneumoniae, Haemophilus influenzae, viruses and other agents. Widespread misuse of antibiotics leads to an emerging antimicrobial resistance, especially to penicillines, but also to macrolides and quinolones [1]. The estimated incidence of this disease varies from 1.6 to 13.4 cases per 1000 inhabitants per year. In the United States, pneumonia is considered to be the sixth most common cause of death. In the period from 1979 to 1994 , the overall rates of death due to pneumonia and influenza increased by $59 \%$ (on the basis of ICD9 classification of mortality data from death certificates) in the United States [2]. Much of this increase is due to a greater proportion of persons aged $>65$ years; however, age-adjusted rates also increased by $22 \%$, which suggests that other factors may have contributed to a changing epidemiology of pneumonia, including a greater proportion of the population with underlying medical conditions at increased risk of respiratory infection [3].

In Europe, the incidence of CAP is known only in small areas of three countries (Spain, UK, and Finland) and in a more representative sample of the entire country in Italy. However, from the available data, it is noticeable that a gradient of incidence from north to south is present in Europe, from 11 per 1000 in Finland [4] down to 1.6 per 1000 in Spain [5] and Italy [6]. It is interesting to note that in Italy the same north-south gradient is present among the different areas of the same country. Moreover, the incidence of pneumonia increases with age with very consistent data in all countries. Estimations of the incidence, based on the reported data in the community, suggest a frequency of $1-5 / 1000$ inhabitants per year, althought there are considerable variations in the estimation of incidence of this disease [6]. Identification of the true CAP incidence is difficult because the condition is not easy to define without access to a chest radiograph. Therefore, many patients are being dignosed and treated without radiographic confirmation. Very common mistakes happen, when other pulmonary diseases are being considered as CAP, unless the disease is being followed to its final outcome. CAP encompasses a range of illness severity from very mild to life-threatening. Most cases are mild and managed in the community where chest radiographs may not be easily available. This disease is more frequent in the under 5 years of age group and least common in persons aged 15-29 [7]. From the mid forties, the frequency rises again until it becomes very common in the elderly.

Precise figures on the health care and economic burden are hard to collect. This happens because these data are related to the incidence of the condition, which is incompletely known, and the way in which the condition interfaces with the health care system, which differs from country to country.

Prospective studies suggest that mortality rates vary from $1-5 \%$ for patients managed at home, up to $15.8 \%$ for patients admitted to hospital and even up to $50 \%$ for patients admitted to the Intensive Care Unit (ICU) [5,8-13].

The burden of disease for CAP is being attributed to high morbidity, mortality and serious health care services utilization and expenditure throughout the world. Community-acquired pneumonia appears more frequently in elderly patients with comorbidities, which in the circumstances of progressively ageing population, leads to longer average length of stay in hospital and increased costs of treatment and medical care. Ageing population and increased life expectancy in patients with chronical diseases and emerging antimicrobial resistance lead to complicated cases of community-acquired pneumonia, which means that in the future the burden and costs of CAP are going to increase.

The main direct costs of illness are generated through patient's hospitalization, and they may be even up to $90 \%$ of overall costs related to CAP. The costs of stay in hospital, antibiotic and oxygen therapy are the most important components of direct costs. These components are influenced greatly by the initial severity of the disease and the course of illness during hospitalization. Comorbidities and complications during treatment have great impact on the overall cost of illness.

Indirect costs of CAP comprise the lost of working days or patient's inability to conduct regular activities, and since CAP is a potentially fatal disease, potential lost of life years. Intangible costs could also be taken into account, even though they are cosidered less important, since CAP is an acute illness. They comprise the loss of self care capability, which is especially notable in older population.

The identification of determinants of high treatment costs could help in defining strat- 
egies of their reduction and more efficient utilisation of the existing resources.

\section{SELECTION OF PUBLISHED EVIDENCE ON CAP COSTS}

The available reports on pharmacoeconomic surveys of CAP prevention, diagnosis and treatment published worldwide are relatively scarce, but still very indicative. They all point out the high costs resulting from the treatment of this disease, as well as significant differences between costs for inpatients and outpatients treatment. According to Guest and Morris' report, published in 1997 [8], the British National Health Service (NHS) spent $£ 1,364.3$ million for treatment of 16.3 million episodes of community-acquired lower respiratory tract infections, out of which $32 \%$ (£ 440.7 million) were spent for CAP treatment. This amount ( $£ 440.7$ million) was spent treating 261,000 annual episodes of CAP; $32 \%$ of these epidoses were inpatient stays, which accounted for $96 \%$ of the total direct costs of CAP and $87 \%$ of total annual costs. Costs for outpatients (corresponding to $68 \%$ of total CAP cases) accounted for only $4 \%$ of total annual costs. This analysis shows that the average cost of managing pneumonia in the UK community is $£ 100$ per episode, while the cost of inpatient treatment varies from $£ 1.700$ to $£ 5,100$ per episode, depending on the length of hospitalization and complications. All estimated costs were calculated according to prices from 1992/1993. According to prices from 1995/1996, the costs have already been uprated from $£ 440.7$ to $£ 480.4$ million.

In 1998 Niederman and colleagues [14] published a retrospective study, which showed that an average cost of CAP treatment in inpatients in the USA is US\$ 7166 , for patients aged $\geq 65$, with an average length of stay of 7.8 days. For patients aged less than 65 , average cost of treatment is US\$6042, and average lenth of stay is 5.8 days. The Authors calculated a total cost of US\$ 8.4 billion (US\$ 4.8 billion for treatment of CAP patients aged $\geq 65$, US $\$ 3.6$ billion for treatment of patients aged less then 65 ). Respectivelly, 95\% (for patients aged $\geq 65$ ) and $81 \%$ (for patients aged $<65$ ) of all CAP treatment costs are generated from inpatient treatment.

Orrick and colleagues [15] reported results from their pharmacoeconomic study in 2004, with 99 CAP inpatients enrolled, treated in USA hospitals. According to the results, mean cost of hospitalization per admission was US\$ $3,490 \pm 3058$, with hospital room/board accounting for largest percentage $(83.7 \%)$, followed by laboratory $(8.1 \%)$, antibacterial (4.6\%), radiology $(2.6 \%)$ and respiratory support cost $(0.9 \%)$. The group treated according to current guidelines of the Infectious Diseases Society of America (1998) had a shorter mean length of hospital stay (4.5 days) and a lower total cost of hospitalization (US\$3009 \pm 2682 ), and lower antibacterial costs (US\$117 \pm 79 ), compared to group of patients which were not treated according to the guidelines (mean length of hospitalization was 6.8 days, mean hospitalization costs US $\$ 4992 \pm 3686$, antibacterial therapy US $\$ 301 \pm 409$ ).

Bartolome and colleagues [9] reported results from population-based study which was conducted in Spain in 2004. According to these results, the mean direct cost of CAP treatment in the hospital setting was $€ 1553 \pm 542$, and the cost structure was dominated by hospitalization, which accounts for $84.4 \%$ of all costs. The cost of treating the same disease for outpatients was $€ 196 \pm 86$. Further analysis of the obtained results and possible cost reductions pointed out that $15.7 \%$ of hospital admissions were estimated as inadequate/unnecessary, and that these patients could have been treated completely as outpatients, while the mean length of stay (10.8 \pm 6.2 days) could have been reduced by 3.5 days, in the most severe cases. The reduction of number of inadequate hospitalizations and length of stay in hospital would lead to overall cost reduction of $17.4 \%$. In conclusion of their analysis, the Authors stated that $22 \%$ of patients could have been discharged from the hospital setting during the first 3 days from admission, and short hospitalizations followed by extension of treatment on other health care system levels (primary health care, ambulatory, home care) should be strongly encouraged.

In the same year (2004), Colice and colleagues [10] published a survey in which they calculated the rate of hospitalization in a sample of 7249 episodes of communityacquired pneumonia recorded in $6415 \mathrm{em}-$ ployed patients. The calculated hospitalization rate was $19.6 \%$, and the mortality rate in hospitalized patients was $9.1 \%$. The mean value of CAP episode treatment cost (including the inpatient and eventual previous ambulatory treatment costs) was US\$10,227 \pm 15,342 , while the mean value of treatmant for outpatients was US\$ $466 \pm 1038$. These costs were significantly higer than the previous estimates. Total annual cost of CAP treatment in the USA is estimated to 12.2 billion US\$. Bauer and colleagues [16] analyzed costs related to CAP from the hospital perspective. The results of their study were published in 2005 and comprised data from 22 hospitals in Germany, with 580 patients treated with stan- 
dard (fluoroquinolones) and non-standard (beta-lactams and macrolides) therapy. Mean length of stay in hospital was $10.8 \pm 5.2$ days $(10.0 \pm 4$ days in patients treated with standard therapy and $11.5 \pm 6$ days in those treated with non-standard therapy). Mean value of all direct expenses was US\$1,250 (in the first group) and US\$1,409 (in the second group), for each CAP episode treatment. In 1997, direct and indirect costs of CAP treatment in Germany were estimated to be equal to 1.64 billion US\$, out of which 983 million US\$ were direct costs and 656 million US\$ were indirect costs (e.g., costs related to employers' losses). Outpatient treatment costs (US\$ 32.8 million for medicaments and US\$ 45.9 million for other treatment costs) were relatively low, while the costs incurred due to the inpatient treatment were estimated at 896 million US\$ (90\% of direct expenses) and they represent significant burden on health care system and insurance.

Reyes and colleagues [11] published a survey in 2008 in which they analyzed cost determinants for inpatient CAP treatment in Spain. The study involved 271 patients, hospitalized due to community-acquired pneumonia. According to available data and calculations, mean value of treatment costs per patient was $€ 1,683$ ( $€ 1,291-2,471)$, while the costs of hospital stay dominated in the total cost structure $(€ 1,286(€ 857-1,714))$, followed by the costs of laboratory analyses $(€ 212$ (€ 171-272)), therapy (€ 187 (€ 114$304))$ and diagnostic procedures $(€ 58$ ( $€ 29$ 122)). Complications occurence and higher PSI (Pneumonia Severity Index) score were related to increased costs, while the age and comorbidities were not. In conclusion, complications - especially hypoalbuminemia and previous hospitalization - were main determinants of high direct costs of CAP hospitalization.

Available data indicate that the percentage of CAP patients treated in hospital setting varies from 18 to $60 \%$ [9]. Numerous and various factors have influence on this, such as: age, comorbidities, hospital availability, social reasons, lack of trust in patient's compliance, and other subjective criteria with crucial impact in the moment of decision making whether the patient will be hospitalized or not. Clinicians tend to hospital admission whenever there is doubt about positive outcome of outpatient treatment [17].

The results of the study also indicate that shorter course hospitalizations did not increase mortality rate after hospital discharge or hospital re-admission rate, but there is no unique opinion regarding the optimal length of stay in hospital for CAP patients [18]. Av- erage duration of antibiotic therapy in outpatients should be 8 to 10 days, for low risk CAP patients [19], but most frequent literature data suggest 14-days antibiotic treatment [9]. According to some studies, intravenous antibiotic treatment lasted 6 to 7 days $[9,20]$. However, intravenuous antibiotic treatment of 2 to 3 days could be equally effective and could lead to reduced length of stay in hospital and reduced expenses in low risk patients [20]. According to data from the literature, time period from clinical resolution to return to normal working activities was even up to 22 to 25 days [9,21], which is attributed to persistance of some symptoms such as fatigue, patient's age but also waiting time until complete radiographic resolution.

In total cost structure, therapy comprises 10 to $15 \%$ of total CAP treatment costs $[9-11,16,18]$. According to Reyes and colleagues [11], 79\% corresponds to antibiotic therapy costs, whereas this percentage varies depending on the type of antibiotic used, severity of disease and estimated complications that could occur. Bauer and colleagues [16] suggested that the use of more expensive antibiotics such as fluoroquinolones may be associated with shorter length of hospitalization and does not induce changes in the total expenditure.

It is interesting to compare the differences in the costs of inpatient and outpatient (ambulatory) treatment of community-acquired pneumonia. Bartolome and colleagues [9] indicate that the expenses of inpatient CAP treatment are 7.9 times higher than those of outpatient treatment, and in case of complications and extended hospitalization, this difference can be even 17 to 51 times higher [8,22,23].

Total costs of CAP treatment in the USA (including indirect ones) are estimated to reach US\$ 12.2 billion, out of which US\$ 10.3 billion count for treatment in the hospital setting (one million of hospitalizations $\mathrm{x}$ US\$ 10,233 , which represents the average cost per patient), and US\$ 1.9 billion count for the cost of outpatient treatment (4.1 million cases $x$ US\$ 466, which is the average cost per ambulatory treated patient with CAP) [10]. The variability of direct costs is mostly influenced by the length of hospitalization. The authors agree that the significant number of CAP episodes can be treated ambulatory, and the great number of hospitalizations could be avoided in that way [9], which could lead to reduction of costs attributed to hospitalization and hospital stay. Strict guidelines compliance would be a significant step in cost reduction, primarily in terms of Pneumonia Severity Index, which enables the stratification of patients in risk categories at the admis- 
sion and facilitates decision making process regarding the place of treatment and therapy which is to be initiated. Results of recent studies indicate that it is possible to shorten the length of hospital treatment without jeopardizing patient's health or influencing the outcome of the disease. Capelastegui and colleagues indicate that the average length of inpatient treatment was reduced from 5.6 days in 2000 and 2001 to 3.7 days in 2006 and 2007 [24]. The important data is that $22 \%$ of patients could be discharged to home treatment (outpatients) during the first three days from the admission and short hospitalizations followed by further treatment and extended care at other health care levels should be seriously concerned (primary health care, home care) [9]. The most significant costs are made during the first 2 or 3 days of inpatient treatment, and afterwards they are followed by cost decrease [18].

Table I summarizes the results of the main studies on CAP cost of illnesss.

\section{COMMUNITY-ACQUIRED PNEUMONIA: FUTURE COST CONTAINMENT STRATEGIES}

There is a certain peculiarity of Serbian health care setting with regards to respiratory diseases. Serbia is a small post-socialist transitional market with heavy burden of centrally planned economy in the past. Even today it reflects to the patterns of health care funding and management [25]. It should not be forgotten that tobacco addiction is widely spread in this Country, with rates that are much higher than OECD average, and this of course affects CAP incidence [26]. Besides, it is one of seldom European societes reporting increase in pulmonary carcinoma incidence [27]. Official statistics for CAP incidence and mortality in Serbia are missing, so we can base our estimations on scarce CAP incidence data reported for Mediterranean countries with similar prevailing lifestyle and underlying behavioral risks (Italy, Spain) $[5,6]$. Serbian budget allocation for health care funding out of gross domestic product available is estimated equal to $9.9 \%$ and some US\$ 419 per person per year, according to available and official WHO statistics for 2009 [7]. Findings of the few local cost of illness estimates among major diseases (type 2 diabetes mellitus, addiction disorders, cancer, risky pregnancies) [28-31], imply that out-ofpocket citizen's expenditure for medical care heavily overweights governmental subventions. CAP is no exception. Based on the experiences from high income economies, we estimate that CAP budget impact in Serbia will grow further in coming years. Reasons for this trend are both the rasing health care expenditure and the higher affordability of services which are likely to affect consumer demand for quality medical care among ordinary citizens [25].

\begin{tabular}{|c|c|c|c|c|c|}
\hline Type of illness & Country & Study type & Results & Costs & Author/year [ref] \\
\hline $\begin{array}{l}\text { Community- } \\
\text { acquired lower } \\
\text { respiratory tract } \\
\text { infections }\end{array}$ & UK & $\begin{array}{l}\text { Prevalence based } \\
\text { burden-of-illness } \\
\text { analysis }\end{array}$ & $\begin{array}{l}\text { Total direct outpatient/ } \\
\text { inpatient medical costs } \\
\text { per episode }\end{array}$ & $£ 100 / £ 1,700-5,100$ & Guest et al, 1997 [8] \\
\hline CAP & USA & $\begin{array}{l}\text { Retrospective } \\
\text { costs- to-the } \\
\text { Health care } \\
\text { system analysis }\end{array}$ & $\begin{array}{l}\text { Average cost of } \\
\text { treatment in inpatients } \\
\text { for patients aged } \\
\geq 65 /<65\end{array}$ & US\$ 7166/\$ 6042 & Niederman et al, 1998 [14] \\
\hline CAP & USA & $\begin{array}{l}\text { Multicentre } \\
\text { observational } \\
\text { study }\end{array}$ & $\begin{array}{l}\text { Mean cost of } \\
\text { hospitalization per } \\
\text { admission }\end{array}$ & US\$ 3,490 $\pm 3,058$ & Orrick et al, 2004 [15] \\
\hline CAP & Spain & $\begin{array}{l}\text { Prospective cost } \\
\text { analysis study }\end{array}$ & $\begin{array}{l}\text { Mean direct inpatient/ } \\
\text { outpatient cost of } \\
\text { treatment }\end{array}$ & $\begin{array}{l}€ 1,553 \pm 542 / € 196 \\
\pm 86\end{array}$ & Bartolome et al, 2004 [9] \\
\hline CAP & USA & $\begin{array}{l}\text { Retrospective } \\
\text { cost-of-illness } \\
\text { study }\end{array}$ & $\begin{array}{l}\text { Mean direct inpatient/ } \\
\text { outpatient cost of } \\
\text { treatment }\end{array}$ & $\begin{array}{l}\text { US\$10,227 } \pm \\
15,342 / \text { US } \$ 466 \pm \\
1,038\end{array}$ & Colice et al, 2004 [10] \\
\hline CAP & Germany & $\begin{array}{l}\text { Retrospective cost } \\
\text { analysis study }\end{array}$ & $\begin{array}{l}\text { Mean direct inpatient } \\
\text { cost of treatment with } \\
\text { standard/non-standard } \\
\text { therapy }\end{array}$ & US\$1,250/US\$1,409 & Bauer et al, 2005 [16] \\
\hline CAP & Spain & $\begin{array}{l}\text { Prospective } \\
\text { observational cost } \\
\text { analysis study }\end{array}$ & $\begin{array}{l}\text { Mean direct inpatient } \\
\text { cost of treatment }\end{array}$ & $\begin{array}{l}€ 1,683(€ 1,291- \\
2,471)\end{array}$ & Reyes et al, 2004 [11] \\
\hline
\end{tabular}


There are several strategies which can possibly contain outpatient pneumonia costs. First of all, it is necessary to highlight the importance of vaccination, especially in the vulnerable population, implementing prophylaxis and pneumococcal and flu vaccination programs [8]. Furthermore, it is important to develop strategies to prevent and minimize hospitalization, by adhering the clinical admission guidelines [8] (reducing the number of inpatients and reducing the lengh of hospital stay), with more effective out of hospital management. The early justified application of antibiotic therapy and the early transfer from intravenous to oral therapy, as well as prevention of complications during the hospitalization are very important [11].

It is certain that such interventions could justify themselves in the Serbian national health sector. Here outsourcing net savings would contribute substantially to resolve ongoing health care funding difficulties [25]. Published data on similar studies conducted in the Balkans examining CAP treatment cost within local clinical setting are missing. Also, there are no data on the degree of initially assessed illness severity, length of hospitalization and the occurence of complications that prolong the hospitalization, increasing the treatment costs and disease mortality rate. Due to the current working environment in health care institutions, in conditions of permanent restriction imposed by the Republic Health Insurance Fund, rational use of health resources has an increasing importance. The long-term problem of health care sector management remains how to provide optimal quantity and quality of population health care by means of limited funds and resources.

\section{ACKNOWLEDGMENTS}

The authors would like to express their gratitude to the Ministry of Education and Science of the Republic of Serbia, for Grant OI $\mathrm{N}^{\circ} 175014$ out of which underlying clinical trials providing basis for this review article were funded.

\section{REFERENCES}

1. Asche C, McAdam-Marx C, Seal B, et al. Treatment costs associated with community acquired pneumonia by community level of antimicrobial resistance. J Antimicrob Chemother 2008; 61: 1162-8. http://dx.doi.org/10.1093/ $\mathrm{jac} / \mathrm{dkn} 073$

2. Pinner RW, Teutsch SM, Simonsen L, et al. Trends in infectious diseases mortality in the United States. JAMA 1996; 275: 189-93. http://dx.doi.org/10.1001/jama.1996.03530270029027

3. Bartlett JG, Dowell SF, Mandell LA, et al. Practice Guidelines for the Management of Community-Acquired Pneumoniain Adults. Clinical Infectious Diseases 2000; 31: 347-82. http://dx.doi.org/10.1086/313954

4. Jokinen $\mathrm{C}$, Heiskanen $\mathrm{L}$, Juvonen $\mathrm{H}$, et al. Incidence of community acquired pneumonia in the population of four municipalities in eastern Finland. Am J Epidemiol 1993; 137: 977-88

5. Almirall J, Bolibar I, Vidal J, et al. Epidemiology of community-acquired pneumonia in adults: a population-based study. Eur Respir J 2000; 15: 757-63. http://dx.doi.org/10.1034/j.1399-3003.2000.15d21.x

6. Viegi G, Pistelli R, Cazzola M, et al. Epidemiological survey on incidence and treatment of community acquired pneumonia in Italy. Respiratory Medicine 2006; 100: 46-55. http://dx.doi.org/10.1016/j.rmed.2005.04.013

7. World Health Organization. Data available at: www.who.int

8. Guest JF, Morris A. Community-acquired pneumonia: the annual cost to the National Health Service in the UK. Eur Respir J 1997; 10: 1530-4. http://dx.doi.org/10.1183/09031936.97.10071530

9. Bartolome M, Almirall J, Morera J, et al. A population-based study of the costs of care for community-acquired pneumonia. Eur Respir J 2004; 23: 610-6. http://dx.doi.org/10.1183/09031936.04.00076704

10. Colice GL, Morley MA, Asche C, et al. Treatment costs of Community-Acquired Pneumonia in an employed population. Chest 2004; 125: 2140-5. http://dx.doi.org/10.1378/chest.125.6.2140

11. Reyes S, Martinez R, Valles JM, et al. Determinants of hospital costs in community-acquired pneumonia. Eur Respir $J$ 2008; 31: 1061-7. http://dx.doi.org/10.1183/09031936.00083107

12. Fine MJ, Smith MA, Carson CA, et al. Prognosis and outcomes of patients with community-acquired pneumonia. A meta-analysis. JAMA 1996; 275: 134-41. http://dx.doi.org/10.1001/jama.1996.03530260048030

13. Marras TK, Jamieson L, Chan CK. Inpatient care of community-acquired pneumonia: the effect of antimicrobial guidelines on clinical outcomes and drug costs in Canadian teaching hospitals. Can Respir J 2004; 11: 131-7 
14. Niederman MS, McCombs JS, Unger AN, et al. The costs of treating community-acquired pneumonia. Clin Ther 1998; 20: 820-37. http://dx.doi.org/10.1016/S0149-2918(98)80144-6

15. Orrick JJ, Segal R, Johns TE, et al. Resource use and cost of care for patients hospitalized with community acquired pneumonia: impact of adherence to infectious diseases society of america guidelines. Pharmacoeconomics. 2004; 22: 751-7. http://dx.doi.org/10.2165/00019053-200422110-00005

16. Bauer TT, Welte T, Ernen C, et al. Cost analyses of Community-Acquired Pneumonia from the hospital perspective. Chest 2005; 128: 2238-46. http://dx.doi.org/10.1378/chest.128.4.2238

17. Porath A, Schlaeffer F, Lieberman D. Appropriateness of hospitalization of patients with community-acquired pneumonia. Ann Emerg Med 1996; 27: 176-83. http://dx.doi.org/10.1016/S0196-0644(96)70320-7

18. Fine MJ, Pratt HM, Obrosky DS, et al. Relation between length of hospital stay and costs of care for patients with community-acquired pneumonia. Am J Med 2000; 109: 378-85. http://dx.doi.org/10.1016/S0002-9343(00)00500-3

19. Frias J, Gomis M, Prieto J, et al. Initial empirical antibiotic treatment of community-acquired pneumonia. Rev Esp Quimioter 1998; 11: 255-61

20. Siegel RE, Halpern NA, Almenoff PL, et al. A prospective randomized study of inpatient iv. antibiotics for community-acquired pneumonia. The optimal duration of therapy. Chest 1996; 110: 965-71. http://dx.doi.org/10.1378/ chest.110.4.965

21. McCormick D, Fine MJ, Coley CM, et al. Variation in length of hospital stay in patients with community-acquired pneumonia: are shorter stays associated with worse medical outcomes? Am J Med 1999; 10: 5-12. http://dx.doi. org/10.1016/S0002-9343(99)00158-8

22. Gonzalez-Moraleja J, Sesma P, Gonzalez C, et al. ¿Cual es el coste de las neumonias que ingresamos inadecuadamente? Arch Bronchoneumol 1999; 35: 312-6

23. Whittle J, Lin CJ, Lave JR, et al. Relationship of provider characteristics to outcomes, process, and costs of care for community-acquired pneumonia. Med Care 1998; 36: 977-87. http://dx.doi.org/10.1097/00005650-199807000-00005

24. Capelastegui A, España PP, Quintana JM, et al. Declining length of hospital stay for pneumonia and postdischarge outcomes. Am J Med 2008; 121: 845-52. http://dx.doi.org/10.1016/j.amjmed.2008.05.010

25. Jakovljevic M, Jovanovic M, Lazic Z, et al. Current efforts and proposals to reduce healthcare costs in Serbia. Ser $J$ Exp Clin Res 2011; 12: 161-3

26. Bumpa JB, Reichb MR, Adeyic O, et al. Towards a Political Economy of Tobacco Control in Low- and MiddleIncome Countries, Health, Nutrition and Population (HNP) Discussion Paper. The International Bank for Reconstruction and Development / The World Bank, 2009

27. Cancer incidence and mortality in central Serbia, Institute of public health of Serbia, Report No. X, Beograd, 2010

28. Biorac N, Jakovljevic M, Stefanovic D, et al. Assessment of diabetes mellitus type 2 treatment costs in the Republic of Serbia. Vojnosanit Pregl 2009; 66: 271-6. http://dx.doi.org/10.2298/VSP0904271B

29. Jovanovic M, Jakovljevic M. Inpatient detoxification procedure and facilities: financing considerations from an Eastern European Perspective. Alcohol 2011; 44: 547-54

30. Jakovljevic M, Varjacic M, Jankovic SM. Cost-effectiveness of ritodrine and fenoterol for treatment of preterm labor in a low-middle-income country: a case study. Value Health 2008; 11: 149-53. http://dx.doi.org/10.1111/j.15244733.2007.00222.x

31. Radovanovic A, Dagovic A, Jakovljevic M. Economics of Cancer Related Medical Care Worldwide estimates and Avalable Domestic Evidence. Arch Oncol 2011; 19: 59-63 